\title{
0 Cine Debate promovendo encontros do cinema com a escola
}

\author{
Andreza Berti* , Rosa Malena Carvalho* *
}

\section{Resumo}

Partindo da hipótese-cinema, de Alain Bergala (2008), reconhecemos o cinema como alteridade, pois a experiência com o cinema permite ser o outro, viver em outro território, flanar por diferentes espaços e tempos. Nesse processo, o cinema pode entrar na escola como potência criadora: promover o encontro dos(as) alunos(as) com diferentes experiências estéticas; provocar a dúvida, o questionamento, colocando em xeque o lugar-comum, os padrões socioculturais, as identidades fixas. A experiência com Cine Debate em escolas públicas de Ensino Médio, nos municípios do Rio de Janeiro e Niterói, permitiu problematizar a produção cinematográfica, favorecer a aproximação do cinema com a escola, contribuir para a ampliação do número de filmes brasileiros assistidos, questionar o que consideramos "olhar". Por meio de uma pesquisa qualitativa, percebemos o desejo dos estudantes em aprofundar os temas discutidos, conhecemos seus gêneros cinematográficos preferidos e a frequência com que assistem a filmes. Esse resultado indica a continuidade da experiência com o Cine Debate.

\section{Palavras-chave}

Cinema; escola; educação do olhar; alteridade.

* Centro Cultural de Ciência e Tecnologia, Universidade Federal do Rio de Janeiro (UFRJ), Rio de Janeiro, RJ, Brasil. andreza@casadaciencia. ufrj.br.

* * Instituto de Educação Física, Universidade Federal Fluminense (UFF), Niterói, RJ, Brasil. rosamalena@vm.uff.br. 


\title{
The cinema-debate promoting encounters between cinema and school
}

\begin{abstract}
Taking as its starting point the hypothesis cinema, by Alain Bergala (2008), we recognize cinema as otherness, because, from experience with the cinema, we can be the other, live in the other's territory, fly through different spaces and times. In this process, the cinema may enter the school as a creative potential; to promote the meeting of students with different aesthetic experiences, to provoke doubts and questioning the commonplace, the social and cultural patterns, the fixed identities. The experience with cinema-debate in public schools in Rio de Janeiro and Niterói, allowed us to discuss cinematographic production, favor the convergence between cinema and school, contribute to increase the number of Brazilian films seen, question what we consider "to look". Through a qualitative research, we could see the students' desire to go deeper into this discussion, to learn about the film genres they prefer and, how often do they go to the movies. These results recommend the continuity of the experience with cinema-debate.
\end{abstract}

Keywords

Cinema; school; education of seeing; otherness. 


\section{Argumento: o cinema}

Se podes olhar, vê.

Se podes ver, repara. ${ }^{1}$

A leitura do livro A hipótese-cinema, de Alain Bergala (2008), convida-nos a pensar o cinema como alteridade. O cinema, como exterior a um eu, possibilita estabelecer relações, promover encontros, produzir afetos.

Ao reconhecermos o cinema como alteridade, estaremos frente à diferença do outro, extraídos do conforto de sermos nós mesmos - sem receio à presença do outro -, questionando a percepção de que permanecemos o mesmo. A experiência com o cinema permite flanar por espaços e temporalidades desconhecidos, convidando a sermos múltiplos, outros e tantos outros. O outro não é apenas "o estrangeiro", "o negro", "o índio”, “a criança”, “o velho”, com o qual preciso conviver. O outro é tudo aquilo que sou e não sou. É a própria diferença encarnada que desterritorializa, territorializa e reterritorializa.

O cinema - por se apresentar como um grande território - permite-nos fazer escolhas. A partir de um filme, por exemplo, podemos ser outro, viver em outro lugar, pertencer a outra cultura. 0 cinema, portanto, pode ser uma frutífera experiência de agenciamento com o outro.

Nesse processo, ao aproximar as experiências ${ }^{2}$, aproximam-se os sujeitos, com diversas possibilidades de ação e de intervenção. A experiência como o que nos acontece potencializa ações educativas (heterogêneas e múltiplas) pela diversidade de situações que são oferecidas e criadas para favorecer esse encontro, visto que produz o sujeito da diferença e da multiplicidade. Nessa direção,

[...] a experiência, a possibilidade de que algo nos passe ou nos aconteça ou nos toque, requer um gesto de interrupção, um gesto que é quase impossível nos tempos que correm: requer parar para pensar, para olhar, parar para escutar, pensar mais devagar, olhar mais devagar, demora-se nos detalhes, suspender a opinião, suspender o juízo, suspender a vontade, suspender o automatismo da ação,

1. Do filme Ensaio sobre a cegueira, lançado em 2008, com direção de Fernando Meirelles.

2. 0 conceito de experiência, utilizado neste artigo, é 0 mesmo atribuído por Larrosa. 0 autor compreende a experiência como o que "nos passa, ou o que nos acontece, ou o que nos toca” (2004, p.154). 
cultivar a atenção e a delicadeza, abrir os olhos e os ouvidos, falar sobre o que nos acontece, aprender a lentidão, escutar os outros, cultivar a arte do encontro, calar muito, ter paciência e dar-se tempo e espaço (Larrosa, 2004, p. 160).

As experimentações com o mundo evidenciam que a diferença não se subordina à identidade como aquilo a que se deve opor, que é preciso negar e ser negado. Ao contrário, a diferença é afirmação. É potência de criação. Ela se refere, pois, “a outras diferenças que nunca a identificam, mas a diferenciam” (Deleuze, 2006, p. 94).

Entender o cinema como diferença e alteridade amplia a noção de cinema como linguagem, indo além das perspectivas tradicionais estruturalistas que estudam a narrativa cinematográfica e a decodificação de signos. Não se trata de fazer uma análise sintática minuciosa do cinema. A atitude estética é de que os espectadores tenham a postura de sujeitos aprendentes diante das obras analisadas, compartilhando as emoções, revelando o cinema como arte, assumindo uma postura criadora. Assim,

[...] o cinema não é língua, universal ou primitiva, nem mesmo linguagem. Ele traz à luz uma matéria inteligivel, que é como que um pressuposto, uma condição, um correlato necessário através do qual a linguagem constrói seus próprios "objetos" (unidades e operações significantes) (Deleuze, 2007, p. 311).

Com esse sentido, o cinema manifesta-se como "arte perturbadora”, pois desestabiliza, desterritorializa, produz afetos. A arte, segundo Bergala (2008, p. 97), é o "que resiste, o que é imprevisível, o que desorienta num primeiro momento. A arte tem que permanecer, mesmo na pedagogia, um encontro que desestabiliza o conjunto de nossos hábitos culturais". Sem dúvida, “a arte deve ser exposta sem risco aos jovens” (Bergala, 2008), pois o cinema, como qualquer outra manifestação artística, não apresenta verdades absolutas, soluções óbvias.

O cinema, com seus filmes, não está aí para “poupar” os espectadores, mas sim, para promover um encontro avassalador com a arte. Graças ao filme, as crianças vivem a experiência da personagem. Identificam-se, incomodam-se, comovem-se... Atuam. 
No filme JLG por JLG - autorretrato (1995), Jean-Luc Godard chama atenção para a regra e a exceção. A partir disso, Bergala (2008, p. 31) argumenta que a arte não "se ensina, mas se encontra, se experimenta, se transmite por outras vias além do discurso do saber, e às vezes mesmo sem qualquer discurso. 0 ensino se ocupa da regra, a arte deve ocupar lugar de exceção". Considerar os espaçostempos ${ }^{3}$ educativos como lócus potentes para o embate crítico da realidade maniqueísta e como campo de atuação transformador é um importante passo para a ressignificação dos processos escolares.

Nesse processo, a arte, por meio do cinema, entra na escola como "um outro", como potência de criação que, por seus "aparatos", como expressão e produção de culturas, pode "oferecer as possibilidades de tentarmos ser outra(s) coisa(s), para além do que já somos, sem deixar de ser o que somos." (Skliar, 2004, p. 86).

A escola, portanto, apresenta-se como um espaçotempo intenso para o encontro dos(as) professores(as) e alunos(as) com a arte cinematográfica, a qual possibilita agenciamentos entre diferentes tempos, espaços, estilos e culturas.

\section{Panorâmica: cinema e escola}

Ainda que a tradição hegemônica nas escolas apresente indícios de práticas padronizadas (a disposição das carteiras; o estabelecimento dos códigos linguísticos com a determinação de quanto tempo os(as) alunos(as) permanecerão sentados e quietos; as filas formadas para entrar, sair, ir ao banheiro, beber água; as subdivisões hierárquicas; as sanções; as punições), é possível perceber, em alguns cotidianos escolares, momentos dedicados às atividades de recreação, de lazer, de arte, de criação.

Por vezes, surgem, no planejamento escolar, situações de aprendizagens significativas e contextualizadas. Entretanto, essas articulações são abordadas de maneiras complementares, isto é, surgem como pano de fundo às aulas de Língua Portuguesa, Matemática, Ciências, História e Geografia. Se o tema da aula for compatível com práticas críticas e criativas, isso pode virar "aula séria". Se não, opta-se pelos exercícios repetitivos e pela clássica educação bancária, que tão bem denunciou Paulo Freire (2005).

Com o cinema não é diferente. Quando ele está presente na escola, geralmente é para se "encaixar" nas aulas e dialogar com os conteúdos, com a perspectiva de incrementar o assunto. Por esse motivo, costuma ser adotado

3. Expressão utilizada na dissertação “A corporeidade no espaçotempo escolar: uma possibilidade na construção rizomática do conhecimento" (Berti, 2009). 
como recurso didático ("serve para" ilustrar os conteúdos, sistematizar temáticas ou despertar interesse pela área). Essa visão restrita não potencializa a alteridade. A experiência com o cinema na escola não se reduz a um campo disciplinar específico, pois a arte provoca um estranhamento na composição escolar rígida.

A nossa cultura aprecia muito a linguagem escrita e a importância de conhecermos uma série de expoentes da literatura, mas a leitura de imagens e a prática de ver e analisar filmes também é de extrema relevância no nosso cotidiano, pois "ver filmes, é uma prática social tão importante, do ponto de vista da formação cultural e educacional das pessoas, quanto à leitura de obras literárias, filosóficas, sociológicas e tantas mais" (Duarte, 2009, p. 16). Se existe esse cuidado com a formação literária dos(as) jovens, é importante dar atenção à escolha dos filmes, a partir do que sabemos sobre cinema.

Embora valorizado, o cinema ainda não é visto pelos meios educacionais como fonte de conhecimento. Sabemos que arte é conhecimento, mas temos dificuldade em reconhecer o cinema como arte (como uma produção de qualidade variável, como todas as demais formas de arte), pois estamos impregnados da ideia de que cinema é diversão e entretenimento, principalmente se comparado a artes "mais nobres". (Duarte, 2009, p. 70-71)

Quando o cinema entra na escola, com a exibição de um filme, por exemplo, não se trata de fazer, com os(as) alunos(as), apenas, uma análise do tema abordado, mas, sim, colocar o cinema em xeque, duvidar. Assumir o lugar do cineasta, questionar por que escolheu este plano e não aquele outro. Por que se optou por esta cena? Ou, "o que ainda era possível antes da decisão”? (Bergala, 2008, p. 131).

Sendo assim, a experiência do/com o cinema não acontece somente por meio de análises de filmes, ou de debates cuidadosamente encaminhados, mas como criação.

É imprescindível que os(as) alunos(as) participem de todo o processo: da concepção à filmagem. Até porque existe uma diferenciação entre o filme e o cinema: o filme é o resultado de uma produção cultural, mas “[...] quando se fala em cinema, está-se falando de um amplo aparato multidimensional que engloba fatos que vêm antes, depois ou por fora do filme [...]" (Duarte, 2009, p. 86). Para que o filme aconteça, é necessário pensar no orçamento, na equipe de filmagem, na locação do espaço, no estúdio, no público, no lançamento, na avaliação, nos relatórios, etc. 
As possibilidades cinematográficas nos espaços escolares permitem entender o processo de constituição dos filmes e, ao mesmo tempo, problematizam as categorias sociais presentes no cotidiano escolar, sem fortalecer os padrões fixos e únicos: quem escreve bem, ficará responsável pela composição dos diálogos e roteiros: menino de porte atlético fará o papel de galã; a liderança da turma será o diretor do filme; o(a) estudante organizado(a) se encarregará da produção; etc.

O cinema, como prática sociocultural, depende do contexto em que é visto ou produzido. Nesse sentido, os filmes trazem uma série de convenções, de representações dos padrões sociais - de masculinidade, de feminilidade, de infância, de etnia, de misticismo, etc. Por isso, é importante

[...]redistribuir minimamente as cartas excessivamente marcadas - na turma e na sociedade em geral - que cabem aos bons e maus alunos, aos fortes e aos fracos, àqueles que tomam a palavra e àqueles que não ousam tomá-la, aos dominantes e aos dominados, aos "herdeiros" e aos culturalmente desfavorecidos, aos "com futuro" e aos "sem futuro". (Bergala, 2008, p. 203).

Mesmo sendo importante a criação cinematográfica coletiva, é fundamental que os(as) estudantes possam passar pela experiência individualmente. Não necessariamente o ensaio individual induzirá a criação de um filme próprio, pois,

[...] em um dado momento, cada um deve ter a responsabilidade inteira e individual de um gesto de criação: rodar um, dois ou três planos, fazer um raccord entre dois planos. É preciso que cada um faça sozinho todas as escolhas, que corra pessoalmente todos os riscos, respeitando a regra do jogo que é comum a todos, mas sem precisar se justificar a ninguém no momento da passagem ao ato. (Bergala, 2008, p. 207).

$\mathrm{Na}$ "passagem ao ato", os(as) alunos(as) assumem toda a incumbência pelas suas escolhas. As atividades que desenvolvem permitem que possam se conhecer, ultrapassar limites, experimentar o novo, cooperar, dialogar, encenar, criar, reinventar, poetizar, ousar. 
A partir da experiência do L'EdenCinéma $a^{4}$, notamos a relevância de um acervo diversificado de filmes realizados ao longo dos anos na história do cinema, para contrastar com os filmes oferecidos pela indústria cultural5. Sendo assim, "a escola tem que propor uma outra cultura, que acabará se tornando - mesmo que involuntariamente - 'alternativa' diante de um cinema imposto cada vez mais maciçamente como 'o todo' do cinema” (Bergala, 2008, p. 96).

Dessa forma, o cinema na escola pode proporcionar, tanto para os(as) professores(as) quanto para os(as) alunos(as), experiências estéticas, diferentes das oferecidas pelo cinema de consumo. Entretanto, os filmes de grande circuito (majoritariamente americanos) são os mais vistos e, consequentemente, os mais exibidos nas salas de aula.

A moderna sociedade ocidental, construída sob a hegemonia da razão instrumental, erigiu um modelo de escola e de currículo inscritos em determinada visão de homem, de sociedade, de tempo, de espaço que circunscrevem a instituição escolar. Associada à expansão e consolidação das sociedades capitalistas, a própria arte inseriu-se na lógica do mercado e da acumulação capitalista, foi apropriada pela dinâmica mercantil e do consumismo. A indústria cultural, a mídia hegemônica, exerce seu poder nos processos de formação do gosto, dos estilos, dos padrões estéticos e culturais, produzindo subjetividades e comportamentos (Azevedo; Teixeira, 2010, p. 19).

Como experiência, portanto, o cinema na escola pode provocar o estranhamento e a invenção, possibilitando diversas experimentações estéticas que promovam novos

4. Segundo Bergala (2008), é uma coleção de DVDs, textos e documentos, que acompanha o "Plano de cinco anos" no campo do cinema, criada pelo Ministério da Educação da França para ser utilizada nas salas de aula.

5. 0 conceito de Indústria Cultural é abordado no livro Dialética do Esclarecimento (1985) de Theodor Adorno e Max Horkheimer, publicado imediatamente após a $2^{\text {a }}$ Guerra Mundial. Nesse livro, os filósofos discutem exaustivamente 0 processo de mercantilização da cultura na sociedade capitalista, o qual padroniza estilos de vida e identidades; capaz de se tornar o "mais sensível instrumento de controle social” (Adorno apud Pucci, 1994, p. 32). arranjos, novas temporalidades e novos sentimentos. Afinal, como produto cinematográfico, o que está no filme existe e é afetado pela sua relação com o mundo.

0 que significa favorecer uma educação que entrelace e produza saberes para o transbordamento da vida. Em movimentos que priorizem as ações, as interações, as emoções e os acontecimentos presentes nos cotidianos escolares. Afinal, 
[...] a educação é, necessariamente, um empreendimento coletivo. Para educar - e para ser educado - é necessário que haja ao menos duas singularidades em contato. Educação é encontro de singularidades. Se quisermos falar espinosanamente, há os bons encontros, que aumentam minha potência de pensar e agir - o que o filósofo chama de alegria - e há os maus encontros, que diminuem minha potência de pensar e agir - o que ele chama de tristeza. A educação pode promover encontros alegres e encontros tristes, mas sempre encontros (Gallo, 2008, p. 01).

Pensar os processos educacionais, nessa perspectiva, é relacionar os diferentes encontros e perceber como esses repercutem na vida em sociedade. Assim, debater a construção do filme e o que é exibido pode ser um convite para pensar, para sentir, para aproximar os sentidos impregnados nas práticas pedagógicas com as relações sociais, políticas, culturais e econômicas que nos afetam e constituem.

\section{Zoom: a experiência com Cine Debate}

É a partir da conversa com diferentes linguagens que se aproximam o cinema e a escola. Nessa perspectiva, a ideia central de inserir o Cine Debate nasce como potencializador dessas transformações, ao promover debates com alunos(as) e professores(as), em torno de temas específicos extraídos de filmes brasileiros. Esses temas são os elementos geradores do diálogo no cotidiano escolar, tendo como objetivos contribuir para o desenvolvimento e para a ampliação das atividades culturais dos sujeitos aprendentes; aproximar diferentes atores sociais; estimular as escolas para a organização de videotecas; divulgar a cinematografia brasileira; incentivar os estudantes a ingressarem na universidade, problematizando o acesso e a permanência deles nessa instituição.

No desenvolvimento do projeto, portanto, o Cine Debate busca promover encontros entre as pessoas e, ao mesmo tempo, aproximá-las das experiências que vivem e produzem em sociedade. Os temas abordados são sugeridos por meio de pesquisa de opinião, ou demandados em virtude de algum acontecimento local ou nacional. Cada execução é dividida em três blocos: a) exibição de filme; b) "roda de conversa" iniciada por convidados(as); c) avaliação.

No desenvolvimento do processo, também há a preocupação para que a produção cinematográfica não seja entendida como consumo, por alunos e alunas das nossas escolas. 0 que significa indagar a forma passiva e hierárquica da relação com o que é 
socialmente elaborado. Por isso, muitas vezes, a participação das pessoas na "roda de conversa" conduz o debate.

Ao querer percorrer o caminho pedagógico anteriormente mencionado, a experiência com o Cine Debate também vai ao encontro de um dos compromissos assumidos pelas Instituições Públicas de Ensino Superior: a indissociabilidade entre ensino, pesquisa e extensão.

Neste artigo, compartilhamos um ensaio que articulou nossas inquietações e pesquisas ao desenvolver dois projetos de extensão, em Instituições Federais de Ensino Superior, embasados pelos referidos pressupostos.

Na primeira proposta a ser relatada aqui, o Cine Debate surge como elemento agregador de um Projeto de Extensão, realizado em escolas públicas de Ensino Médio do estado do Rio de Janeiro, que inclui diversas Unidades Acadêmicas de Instituição Pública Federal de Ensino Superior, com a finalidade de divulgar e popularizar a ciência nas escolas.

Organizado por uma unidade extensionista de uma dessas Instituições Federais de Ensino Superior, um espaço não escolar, mas, sobretudo, educativo. Esse espaço de educação não formal (ambiente compartilhado de forma intencional, mas não regulamentado por Sistemas de Ensino), propõe-se a promover o debate acerca da divulgação e da popularização da ciência. Por meio de uma linguagem acessível e diversificada, convida-se o público a problematizar as questões científicas contemporâneas por intermédio de atividades de experimentação, desmistificando o estereótipo que se tem dos cientistas; revelando aos(às) estudantes o processo não linear repleto de rupturas, disputas e transformações do "fazer ciência"; e favorecendo ambientes não escolares como espaçostempos de formação e de socialização.

O Cine Debate, que articulou os dois projetos de extensão mencionados, foi este primeiro aqui apresentado - pela parceria com uma Instituição Federal de ensino vinculada a uma Administração Militar no Rio de Janeiro que, apesar da ligação, não tem como objetivo formar para a carreira militar. E, também, o primeiro Itinerante do outro aqui exposto (quando esse projeto extensionista circula nas escolas públicas).

A unidade escolar em que aconteceu esse Cine Debate se localiza em um bairro

6. Informações disponibilizadas no site <http://portalgeo.rio.rj.gov.br/bairroscariocas〉. Acesso em: 01 jul. 2011. 7. 0 IDS foi inspirado no Índice de Desenvolvimento Humano (IDH). Sua finalidade é medir o grau de desenvolvimento social de uma determinada área geográfica em comparação com outras de mesma natureza. da zona norte, com uma população aproximada de 212.000 habitantes ${ }^{6}$ e ocupa um lugar favorável no ranking do Índice de Desenvolvimento Humano (IDH) e no Índice de Desenvolvimento Social (IDS) ${ }^{7}$ do município do Rio de Janeiro. 
Na última divulgação dos dados do Índice de Desenvolvimento da Educação Básica (IDEB) ${ }^{8}$, divulgados pelo Ministério da Educação, em 2009, a instituição obteve nota 7,5. Acima da média do IDEB das escolas da região que ficam em torno de 4,5 .

A escola oferece Ensino Fundamental e Médio; tem um pouco mais de 2.000 alunos(as), com serviços de orientação psicopedagógica e apoio técnico-pedagógico; um auditório com 180 lugares; sala de leitura; laboratórios de Física, Química, Biologia e Informática; salas de vídeo; sala de Artes Plásticas; quadras poliesportivas; campos de futebol; e horta para o primeiro segmento.

Nesse contexto, o Cine Debate foi realizado com cerca de 100 estudantes do Ensino Médio, exibindo o filme $5 X$ favela: agora por nós mesmos`. Essa exibição visibilizou um projeto social e cinematográfico que colocou em foco jovens moradores das comunidades cariocas, ao protagonizarem nas telas suas intensidades, inquietudes, desejos e potências. As produções foram orientadas por Cacá Diegues e outros renomados cineastas, precursores do movimento brasileiro intitulado "cinema novo", a partir do longa-metragem 5 X favela, lançado no início da década de 60.

0 olhar atento dos(as) alunos(as) para o filme, assim como as questões levantadas, fizeram-nos considerar um resultado favorável, motivando-nos a organizar uma imediata realização de um segundo Cine Debate para confrontar os resultados. 0 que aconteceu com a parceria de uma instituição da rede pública estadual de ensino no Rio de Janeiro.

Essa outra unidade escolar se localiza na região metropolitana do estado, em $\mathrm{Ni}$ terói - cidade com aproximadamente 480.000 habitantes (a sexta cidade mais populosa do Rio de Janeiro) e a de maior IDH, segundo os dados do Instituto Brasileiro de Geografia e Estatística (IBGE). Além disso, a cidade tem a maior taxa de escolaridade e nível de alfabetização do estado e uma das maiores do país. ${ }^{10}$

Entretanto, a escola está em um bairro da cidade com predominância das habitações na área da favela, com baixa taxa de alfabetização em relação a outros lugares, ocupando $043^{0}$ lugar no conjunto do município ${ }^{11}$. De acordo com os dados do IDEB do ano de 2009, a instituição obteve nota 3,3 - inferior à média do IDEB da cidade.

8. Indicador da qualidade da educação brasileira, avaliado pelo Instituto Nacional de Estudos e Pesquisas Educacionais Anísio Teixeira (INEP), calculado a partir dos dados sobre aprovação escolar, obtidos no Censo Escolar e as médias de desempenho no Saeb (para os Estados e o Distrito Federal) e a Prova Brasil (para os municípios).

9. Filme brasileiro, lançado em 2010, dirigido por um grupo de jovens cineastas moradores de favelas do Rio de Janeiro.

10. Essas informações constam no site do IBGE 〈http:// www.ibge.gov.br/cidadesat/topwindow.htm?1>. Acesso em: 28 nov. 2011.

11. Informações extraídas de: 〈http://www.urbanismo. niteroi.rj.gov.br/.> Acesso em: 29 nov. 2011. 
A unidade escolar funciona nos três turnos, tem em torno de 1.500 alunos(as) e contempla o segundo segmento do Ensino Fundamental e o Ensino Médio regular, além de oferecer Educação de Jovens e Adultos. A escola não dispõe de auditórios e/ ou salas de vídeo e leitura. Aqui também o Cine Debate foi bem acolhido.

Considerando o panorama dessas escolas, a inserção do Cine Debate aconteceu por meio da exibição de filme e, em seguida, um professor (da própria escola) e a Coordenadora do Projeto de Extensão Itinerante (o que representa um professor de outra instituição), mediados pela coordenadora do outro projeto de extensão aqui relatado, discutiram a temática do filme, previamente definida pela coordenação do evento. A escolha do(a) professor(a) da unidade escolar esteve diretamente relacionada ao seu envolvimento com projeto de cinema na instituição ou à temática apresentada pelo filme.

Quanto à organização, as sessões seguiram as seguintes etapas: $1^{\underline{a}}$ - Apresentação do filme: exposição, antes de cada projeção, de elementos gerais do filme: sua ficha técnica, sinopse e outras informações. $2^{\underline{a}}$ - Projeção: exibição, propriamente dita, do filme. $3^{\underline{a}}$ - Debate: apresentação e discussão, quando os debatedores buscaram articular o tema com a obra cinematográfica, abrindo à participação do público para perguntas, acréscimos e críticas. $4^{\underline{a}}$ - Avaliação: análise do encontro a partir de questionários com respostas abertas e de múltipla escolha.

Para o momento inicial do projeto, trabalhamos apenas com o primeiro episódio “Fonte de Renda" ${ }^{12}$ do 5 X favela: agora por nós mesmos. Como a atividade teria uma hora e meia de duração, optamos por disponibilizar um período maior para o debate, a fim de que pudéssemos explorar a estética, o tema, o contexto e a produção do filme.

Esse quadro conta a história de Maicon, aluno egresso da rede pública de ensino, morador de uma comunidade do Rio de Janeiro, que consegue realizar o sonho de passar no vestibular, mas logo se depara com a questão: vender drogas para os colegas de faculdade, como forma de obter o sustento necessário para a compra de livros, alimentação e transporte.

No início da atividade, enquanto os(as) alunos(as) se organizavam no espaço do auditório, passavam, no projetor, a ficha técnica do filme, a sinopse dos cinco episódios e os nomes dos convidados para a discussão. Logo que iniciamos, conversamos um pouco com o grupo sobre o projeto, o que aconteceria ali naquele mo-

12. Episódio dirigido por Wagner Novais e Manaíra Carneiro, com aproximadamente vinte minutos. mento e alguns encaminhamentos para o filme e para o debate. 
Os estudantes assistiram, com bastante entusiasmo, ao primeiro episódio e, ao seu término, esboçaram descontentamento com o fim tão breve, o que sinalizou a vontade/disponibilidade para o filme, o interesse pela narrativa. Isso nos estimulou a encorajá-los a alugar a película para assistir aos quatro seguintes episódios.

Logo após a exibição, cada professor falou por dez minutos, destacando o que julgara importante para provocar os(as) alunos(as) ao debate. Alguns estudantes, timidamente, expressaram seus anseios, dúvidas e questionamentos com relação ao personagem Maicon. Alguns se centraram no que poderia ter acontecido. Outros questionaram, moralmente, a atitude de Maicon. Enfim, o debate apontou diversas faces do outro: o personagem do filme, o colega ao lado, o professor ou o(a) próprio(a) aluno(a).

Um dos destaques dos debates foi quando as pessoas se identificarem com cenas e situações que normalmente não são percebidas no cotidiano. Talvez pela discussão provocada, talvez por um detalhe de uma cena ou mesmo um "estalo", como diz Barthes (1984). Isso pôde ser observado em cenas como a do Rio Card zerado $^{13}$ e na imagem preconcebida que colegas da faculdade fazem de Maicon, por ser morador de favela...

Ao fim do Cine Debate, realizamos algumas avaliações com os(as) alunos(as) para que pudéssemos ter uma pequena impressão do público, saber se a experiência fora válida, quais os gêneros cinematográficos preferidos por eles(as) e a frequência com que assistem a filmes.

Os estudantes que participaram do projeto eram alunos(as) do $2^{\circ}$ e $3^{\circ}$ ano do Ensino Médio e tinham entre 16 e 18 anos. Mais de 90\% dos(as) jovens aprovaram a dinâmica do Cine Debate, expressaram a importância da conversa sobre o filme, perguntaram, argumentaram...

0 resultado da avaliação surpreendeu de forma positiva, pois, na primeira escola, ao entrar no auditório, os alunos mostraram-se preocupados com os "simulados" preparação para o Enem e vestibular - que fariam proximamente e, na segunda, desmotivados com a volta às aulas após longo período de greve dos(as) professores(as).

Nesses grupos, a média de filmes assistidos por mês é em torno de cinco filmes. Outro ponto a ser considerado é o tipo de gênero cinematográfico preferido pelos(as) alunos(as): é grande o interesse pelos estilos de comédia e de ação, enquanto o documentário é o que menos atrai.

A avaliação qualitativa, possibilitada por 13. Cartão de acesso aos transportes públicos no Rio de Janeiro. 
observação e pelo questionário ao final do Cine Debate, permitiu compreender a importância da aproximação cinema e escola, uma vez que o argumento do filme foi discutido em diálogo com o contexto sociocultural dos(as) alunos(as) e professores(as) presentes.

Dialogando com o Cine Debate de outra Instituição Pública Federal de Ensino Superior, um Projeto de Extensão tem buscado expandir suas ações na comunidade, prestando serviço tanto de utilidade pública como de efetivação de um campo de pesquisa e extensão da produção do conhecimento na área da Educação Física Escolar para os(as) alunos do curso de Licenciatura.

O projeto objetiva, por intermédio da exibição de filme, seguida de debate, problematizar as formas hegemônicas sobre corpo, atividades esportivas e de lazer, bem como os processos educacionais e sociais. Como os corpos aparecem nas telas? 0 que expressam do nosso contexto socioeducacional?

Quando relacionamos práticas corporais e conjuntura sócio-histórica, ao focar e desfocar essas questões nos filmes exibidos e debatidos, reiteramos que o "[...] primeiro pressuposto de toda existência humana e, portanto, de toda a história, é que todos os homens devem estar em condições de viver para poder "fazer história" [...]" (Marx; Engels, 2006, p. 53). 0 que significa questionar as concepções que afastam as pessoas dos processos - descorporificando os sujeitos das práticas sociais, afirmando ideias neutras de ser e estar na educação e na sociedade.

As narrativas cinematográficas, ao mostrar corpo e práticas corporais, podem fazer parte do processo de educar o olhar para essas questões como parte do que é socialmente produzido e, ao mesmo tempo, questionar as ideias hegemônicas, criar novos sentidos e modos de narrar os seres humanos e suas formas de ser, relacionar, expressar, dançar, conviver etc.

Assim, filmes sobre culturas urbanas juvenis, gêneros, sexualidades, esportes, etc podem provocar estranhamento e aproximação com formas de ser e agir. Nesse processo, encaminhamos uma educação que deseja indagar a habitual domesticação do olhar, como diz Oliveira (1998).

Como ocorreu com o filme Menino do Rio ${ }^{14}$, exibido com a intenção principal de discutir a relação entre a constituição dos espaços urbanos e o surgimento (e/ou transformação) de práticas esportivas e de lazer. No entanto, a estética e a velocidade

14. Produção brasileira de 1982, dirigida por Antonio Calmon. do filme chamaram atenção para a corporeidade dos personagens masculinos (considerados muito 
diferentes dos atuais: pouco musculosos e menos agressivos) e para o comportamento das personagens jovens (reconhecidamente atores mais velhos, hoje). Essas diferenças fizeram os(as) alunos(as) indagarem a juventude dos(as) professores(as) presentes... Experiência que aproxima o cinema com o conceito de alteridade, mencionado no início deste artigo.

O Cine Debate com o filme Josué de Castro, Cidadão do Mundo ${ }^{15}$ também possibilitou perceber o estranhamento provocado - dessa vez, não pela estética do filme, mas pelo conteúdo e pelas pessoas que conduziram o debate. Fazendo parte da Semana Acadêmica da Universidade, a exibição trouxe alunos(as) e professores(as) de diferentes unidades acadêmicas ao Instituto de Educação Física. Muitos se surpreenderam com a discussão encaminhada por professores(as) e alunos(as) da Licenciatura em Educação Física - o que nos fez pensar o quanto ainda predomina o entendimento dos corpos e das práticas corporais como algo menor, em dissonância com o processo de produzir conhecimento. Ideias veiculadas por meio de uma visão de mundo que entende tudo e todos de forma descontextualizada, fragmentados em partes - frutos de ideário linear e cartesiano que hierarquiza as pessoas e os saberes.

A discussão de dicotomia corpo-mente, de juventude, de intergeracionalidade e de masculinidade, apontada nesses Cine Debates, exemplifica a densidade e a dificuldade que é discutir e perceber o corpo como fenômeno sócio-histórico. Nossas capacidades de andar, comer, respirar, olhar, etc - habitualmente entendidas apenas como biológicas -, ganham diferentes sentidos, valores, atribuições produzidas e compartilhadas em determinado contexto e época. Ao aproximar essas ideias dos processos educacionais, passamos a entendê-los

[...] como lugares de encontros, com singularidades advindas das experiências de cada um, podendo inserir-se numa política de educação facilitadora de propostas curriculares que consideram as corporeidades dos seus sujeitos, propiciando diálogos entre conhecimentos e potencializando saberes dos cotidianos como integrantes da socialização e aprendizagens das crianças, dos jovens e dos adultos, com necessidades especiais ou não. 0 que significa mais do que "preparar cidadão", um exercício de cidadania... (Carvalho, 2012, p. 43).

15. Documentário brasileiro dirigido por SilvioTendler $\mathrm{e}$ lançado em 1994. 
Isso sinaliza a importância de ensaios, como os registrados nesse artigo, que envolvem diferentes sujeitos, saberes e instituições.

Notamos, portanto, a relevância da continuidade dessa experiência, cujos indicativos anteriormente apresentados favorecem a criação de possibilidades educativas marcadas pela multiplicidade, pela diferença e pela alteridade, o que repercute em nosso processo de formação e de reconhecimento, pois “construímos nossa narrativa por meio de ecos de outras narrativas [...]" (Manguel, 2001, p. 28).

Assim, ao finalizar este artigo, desejamos que a narrativa, aqui realizada, contribua para fortalecer a aproximação do cinema com práticas pedagógicas que possibilitem novas experiências escolares, e promova indagações, criações e, nesse processo, encontros com as diferenças - nas telas e fora delas... 


\section{Referências bibliográficas}

AZEVEDO, A. L.; TEIXEIRA, I. Os professores e o cinema na companhia de Bergala. Revista Contemporânea de Educação - Dossiê, cinema e educação. Faculdade de Educação, Universidade Federal do Rio de Janeiro, v. 5, n. 10, jul./dez. 2010.

BARTHES, R. A Câmara Clara. 8. ed. Rio de Janeiro: Nova Fronteira, 1984.

BERGALA, A. A hipótese-cinema: pequeno tratado de transmissão do cinema dentro e fora da escola. Rio de Janeiro: Booklink; CINEAD-LISE -FE/UFRJ, 2008.

BERTI, A. A corporeidade no espaçotempoescolar: uma possibilidade na construção rizomática do conhecimento. Dissertação (Mestrado)-Programa de Pós-Graduação em Educação, Unimep, Piracicaba, 2009.

CARVALHO, R. M. Corporeidade e cotidianidade na formação de professores. Niterói: Editora da UFF, 2012.

DELEUZE, G. A imagem-tempo. Tradução Eloisa de Araújo Ribeiro. São Paulo: Brasiliense, 2007.

DELEUZE, G. Diferença e repetição. 2. ed. Rio de Janeiro: Graal, 2006.

DUARTE, R. Cinema \& educação. 3. ed. Belo Horizonte: Autêntica, 2009.

FREIRE, P. Pedagogia do oprimido. 40. ed. Rio de Janeiro: Paz e Terra, 2005.

GALLO, S. Eu, o outro e tantos outros: educação, alteridade e filosofia da diferença. In: CONGRESSO INTERNACIONAL COTIDIANO: DIÁLOGOS SOBRE DIÁLOGOS, 2., 2008, Niterói. Anais... Rio de Janeiro: Universidade Federal Fluminense, 2008.

LARROSA, J. Linguagem e educação depois de Babel. Belo Horizonte: Autêntica, 2004.

MANGUEL, A. Lendo Imagens. 2. ed. São Paulo: Companhia das Letras, 2001.

MARX, K.; ENGELS, F. A ideologia alemã. Feuerbach - a contraposição entre as cosmovisões materialista e idealista. Tradução Frank Muller. São Paulo: Martin Claret, 2006.

OLIVEIRA, R. C. O trabalho do antropólogo. São Paulo: UNESP/Paralelo 15, 1998.

PUCCI, B. (Org.). Teoria crítica e educação. A questão da formação cultural na escola de Frankfurt. Rio de Janeiro: Vozes, 1994.

SKLIAR, C. A materialidade da morte e o eufemismo da tolerância: duas faces, dentre as milhões de faces, desse monstro (humano) chamado racismo. In: GALLO, S.; SOUZA, R. M. de (Org.). Educação do preconceito: ensaios sobre poder e resistência. Campinas, SP: Alínea, 2004. p. 69-90.

Submetido à publicação em og de agosto de 2012.

Aprovado em 21 de março de 2013. 
200 